\title{
ASTROCYTES IN PRIMARY CULTURE HAVE CHEMICALLY ACTIVATED SODIUM CHANNELS ${ }^{1}$
}

\author{
CHARLES L. BOWMAN,${ }^{*}+2$ HAROLD K. KIMELBERG,${ }^{*}$ MARIA V. FRANGAKIS, ${ }^{*}$ \\ YOHEVED BERWALD-NETTER,§ AND CHARLES EDWARDS $\ddagger$ \\ * Division of Neurosurgery, Albany Medical College, Albany, New York 12208, $¥$ Neurobiology Research Center and the \\ Department of Biological Sciences, State University of New York at Albany, Albany, New York 12222, and §Biochemie Cellulaire, \\ College de France, 75231 Paris Cedex 05, France
}

Received September 21, 1983; Revised January 13, 1984; Accepted January 16, 1984

\begin{abstract}
The effects of two neurotoxins, veratridine and $\alpha$-scorpion toxin II, on the resting potential (RMP) of identified astrocytes in primary cell culture were studied using standard electophysiological techniques. Veratridine caused either a series of transient depolarizations or a single sustained depolarization. $\alpha$-Scorpion toxin (II), which alone had no effect on the RMP, increased the duration of the veratridine-induced transient depolarizations. The depolarization caused by veratridine, or veratridine plus $\alpha$-scorpion toxin II, was reversibly inhibited by tetrodotoxin and was reversibly reduced in magnitude by reductions of the external sodium concentration. Cells that were depolarized by veratridine were shown to contain glial fibrillary acidic protein, a marker considered specific for astrocytes. The effect of long-term $(10 \mathrm{sec})$ hyperpolarizing and depolarizing current pulses on the RMP were also studied using two microelectrodes, i.e., dual impalement. In the absence of veratridine, the RMP returned to its original value after termination of the hyperpolarizing current, and the current-voltage relationship was found to be linear over a wide range of membrane potentials. In the presence of veratridine, termination of the hyperpolarizing current produced a transient depolarization that was sensitive to tetrodotoxin. Depolarizing current pulses were without effect. These results show that astrocytes in primary culture have a chemically inducible $\mathrm{Na}^{+}$channel that appears to be voltage-dependent.
\end{abstract}

Astroglial cells in primary cultures from rodent brain have negative membrane potentials of around $-70 \mathrm{mV}$ and show a linear current-voltage relationship (Kimelberg et al., 1979, 1982b; Moonen et al., 1980), i.e., they lack the voltage-dependent conductances usually present

\footnotetext{
${ }^{1}$ This research was partially supported by National Institutes of Health Grants NS 07681 (C. E.) and NS 19492 (H. K. K.) and by National Science Foundation Grant BNS 8213873 (H. K. K.). We are most grateful to Drs. F. Couraud and H. Rochat for a generous gift of $\alpha$-scorpion toxin II, to Drs. William Shain and George Brown for their gifts of veratridine, to Dr. David $O$. Carpenter for a gift of veratrine, and to Dr. Lawrence F. Eng for his generous gift of rabbit antiserum to human glial fibrillary acidic protein. We thank Drs. Robert S. Bourke, David O. Carpenter, Ko-Ichi Enomoto, William Shain, and N. Traverse Slater for their comments and criticisms of earlier versions of this manuscript, Dr. Gary Strichartz for suggesting the anode break experiment and Dr. James Huston for helpful discussions and a gift of bovine glial fibrillary acidic protein. We thank Dr. Gary Banker for use of his diamond object marker and Dr. Peter Del Vecchio for use of his Nikon "Labophot" microscope. Accounts of some aspects of this work were presented at the annual meeting of the Biophysical Society (Bowman et al., 1983a) and at the annual meeting of the Society for Neuroscience (Bowman et al., 1983b).

${ }^{2}$ To whom correspondence should be addressed.
}

in nerve and muscle. These properties correspond to the electrophysiological characteristics of these cells in situ (Somjen, 1975; Orkand, 1977). Such cultures also show other characteristics similar to those shown by astrocytes in situ (Schousboe, 1980; Hertz, 1982; Kimelberg, 1983). However, veratridine and $\alpha$-scorpion toxin (ScTx(II)) have been reported to increase the uptake of ${ }^{22} \mathrm{Na}$ in astroglial cells in secondary or tertiary cultures derived from mouse brain (Berwald-Netter et al., 1983) and the uptake of radiolabeled guanidinium by glial cells from rat brain (Reiser et al., 1983). This uptake is sensitive to tetrodotoxin (TTX), a specific inhibitor of voltage-dependent sodium channels (see Narahashi, 1974). In nerve and muscle, veratridine facilitates the activation of the voltage-dependent sodium conductance and delays its inactivation (Ulbricht, 1969), while Sc'Tx(II) delays the inactivation of the sodium conductance (Koppenhoffer and Schmidt, 1968). Therefore, it seemed appropriate to study the effects of veratridine and ScTx(II) on the resting membrane potential of astrocytes in primary culture. $^{3}$

\footnotetext{
${ }^{3}$ During the preparation of this manuscript, Reiser and Hamprecht (1983) reported an electrophysiological and tracer study of a polyploid
} 


\section{Materials and Methods}

Cell culture. Astrocytes were grown in primary culture as described previously (Kimelberg et al., 1979, 1982a; Kimelberg, 1983). Briefly, the cerebral hemispheres of new born rats were removed, the meninges were carefully dissected off, and the tissue was dissociated with Dispase (Boehringer-Mannheim, New York, NY) following the method of Frangakis et al. (1981). Occasionally, trypsin was used to dissociate the tissue. The dissociated cells were seeded at $1.3 \times 10^{4}$ viable cells $/ \mathrm{cm}^{2}$ on glass coverslips placed in plastic culture dishes and grown for 2 to 5 weeks in Eagle's basal medium $+10 \%$ fetal calf scrum (GIBCO, Grand Island, New York) at $37^{\circ} \mathrm{C}$ in a $5 \% \mathrm{CO}_{2} /$ $95 \%$ air atmosphere. For electrophysiological experiments, the growth medium was replaced with a HEPESbuffered Ringer's solution containing $122 \mathrm{mM} \mathrm{NaCl}, 3.8$ $\mathrm{mM} \mathrm{KCl}, 1.2 \mathrm{mM} \mathrm{KH}_{2} \mathrm{PO}_{4}, 1.3 \mathrm{mM} \mathrm{CaCl}_{2}, 0.4 \mathrm{mM} \mathrm{MgSO}_{4}$, $10 \mathrm{~mm}$ glucose, and $25 \mathrm{~mm}$ HEPES, pH 7.4, adjusted with $\mathrm{NaOH}$ (total $\mathrm{Na}^{+}$concentration was $140 \mathrm{mM}$ ). After a minimum of $1 \mathrm{hr}$ of exposure to HEPES-Ringer solution, 10 to $30 \%$ of the cells rounded up, making these suitable for impalement. Approximately 80 to $95 \%$ of these rounded-up cells stain for glial fibrillary acidic protein (GFAP) (Stieg et al., 1980; C. Bowman and H. $\mathrm{K}$. Kimelberg, unpublished observations), a marker considered specific for astrocytes (Schachner et al., 1977; Bignami et al., 1980; Eng, 1980).

Electrophysiology. These studies were carried out essentially as described previously (Kimelberg et al., 1979). Cells were impaled with conventional microelectrodes made with a Brown-Flaming micropipette puller (Sutter Instruments, San Francisco, CA) using borosilicate glass tubing from W-P Instruments (New Haven, CT, Catalogue no. 1B100F) and were filled with $1 \mathrm{M} \mathrm{KCl}, 0.5 \mathrm{M}$ $\mathrm{K}_{2} \mathrm{SO}_{4}$, or $0.05 \mathrm{M} \mathrm{K}_{2} \mathrm{SO}_{4}$ in $5 \mathrm{mM}$ HEPES, $\mathrm{pH} 7.25$. The $\mathrm{K}_{2} \mathrm{SO}_{4}$-filled microelectrodes were used for the immunocytochemistry experiments (see "Localization and immunocytochemistry of impaled cells"). The electrode resistances ranged from 30 to 100 megohms when measured in Ringer's solution using a 1-sec pulse of positive current $\left(1 \times 10^{-9} \mathrm{~A}\right)$. Potentials were measured using a W-P Instruments KS-700 electrometer connected to a Grass (model 79D) or a Gould Brush 220 chart recorder for one series of experiments (see Fig. 5). The input impedance of the KS-700 was $5 \times 10^{11}$ ohms as measured by another electrometer (model 610C, Keithley Instruments, Cleveland, $\mathrm{OH}$ ). The cells, growing on glass coverslips, were inserted in a plastic perfusion chamber and viewed using a Nikon "MS" or "Diaphot" inverted microscope equipped with Hoffman modulation contrast optics (final magnification was $\times 600$ ). The tempeurature in all experiments was maintained at 35 to $37^{\circ} \mathrm{C}$ by heating the room.

To impale the cells, the tip of the microelectrode was positioned a few microns away from the rounded-up astrocyte using Brinkmann micropositioners (Brinkmann Instruments, Westbury, NY, catalogue no. 06-2014) attached to a large column $\mathrm{C}$ stand (Brinkmann

clone derived from a virus-induced fusion of $\mathrm{C}_{6}$ glioma cells. They found that veratridine depolarized the cells in a manner similar to the effects reported here for primary astrocyte cultures.
Instruments), and it was gradually advanced into the cell membrane by using a piezoelectric device (Burleigh Pusher, F. Haer and Co., Brunswick, ME). This usually resulted in the formation of a visible pocket in the membrane with a few millivolts positive or negative deflection in the apparent tip potential. After the pocket was formed, the negative capacitance device on the KS 700 electrometer was momentarily activated (about 1 sec), usually resulting in the appearance of a large negative potential $(-60 \pm 13 \mathrm{mV} ; n=103$ cells $)$ which stabilized within a few minutes. We could routinely record from a single cell for several hours.

Immunocytochemistry. Cells growing on glass coverslips were stained for GFAP using a modification of our previously reported procedure (Stieg et al., 1980; Kimelberg et al., 1982a). Cells were first left for $2 \mathrm{hr}$ in the HEPES-buffered medium in $95 \%$ air $/ 5 \% \mathrm{CO}_{2}$ at $37^{\circ} \mathrm{C}$ and then were fixed in ice-cold $4 \%$ paraformaldehyde in $0.1 \mathrm{M}$ cacodylate buffer ( $\mathrm{pH} 7.4$ ). The cells were then immersed for $3 \mathrm{~min}$ in acetone at $-10^{\circ} \mathrm{C}$ and were then rinsed three times in ice-cold phosphate-buffered saline (PBS) which contained $140 \mathrm{mM} \mathrm{NaCl}, 3.5 \mathrm{mM} \mathrm{NaH}_{2} \mathrm{PO}_{4}$, $12 \mathrm{mM} \mathrm{Na} \mathrm{HPO}_{4}, \mathrm{pH}$ 7.25. A 1:50 dilution of rabbit antiserum directed against human GFAP (Eng and Rubinstein, 1978) in PBS was applied to the cell monolayer for $5 \mathrm{~min}$, and the cells were again washed three times in ice-cold PBS. Next, swine anti-rabbit immunoglobulin conjugated with rhodamine (Accurate Chemical and Scientific Corp., Westbury, NY) (diluted 1:100 in PBS) was applied to the cells and left for $5 \mathrm{~min}$. Finally, the coverslips were rinsed three times in PBS at room temperature and were mounted with 50\% glycerol in PBS. Controls were established by (1) substituting nonimmune rabbit serum in the place of anti-GFAP, (2) preabsorbing the anti-GFAP with bovine GFAP or, (3) leaving out the primary antibody.

Localization and immunocytochemistry of impaled cells. In some experiments the cells were photographed (Tri$\mathrm{X}$ film, Kodak, Rochester, NY) before, during, and after impalement. The location of the cell was marked using a diamond object marker (Leitz Inc., Rockleigh, NJ) to scratch a circle on the underside of the coverslip around the cell. The scratch mark was also photographed. The film was developed in Microdol-X $\left(15 \mathrm{~min}, 70^{\circ} \mathrm{F}\right)$. The coverslips were then stained for GFAP (see "Immunocytochemistry") and were viewed with a Nikon Labophot microscope equipped with phase optics and the appropriate filters for rhodamine fluorescence. The scratch marks were easily found, and the cells were identified with the aid of the photographs taken during the electrophysiological recordings.

In the initial experiments, we did not observe the filamentous pattern characteristic of GFAP when we used microelectrodes filled with $1 \mathrm{M} \mathrm{KCl}$. The use of the $\mathrm{KCl}$-filled microelectrodes resulted in staining that had an amorphous quality similar to, but usually more intense than, the controls. Since the majority of the nonimpaled cells showed a filamentous pattern, and since the state of the filaments is very sensitive to ionic strength as well as $\mathrm{pH}$ (Bignami et al., 1980), it seemed possible that leakage of $\mathrm{KCl}$ from the $1 \mathrm{M} \mathrm{KCl}$-filled microelectrodes was disrupting the glial filaments. 
Therefore, we decided to use another electrolyte and arbitrarily chose $\mathrm{K}_{2} \mathrm{SO}_{4}$. Cells impaled with electrodes filled with $0.05 \mathrm{M} \mathrm{K}_{2} \mathrm{SO}_{4}$ and buffered with $5 \mathrm{mM}$ HEPES ( $\mathrm{pH} 7.25)$ showed filamentous staining characteristic of GFAP. However, these electrodes were generally more noisy and prone to changes in tip potential. Occasionally, we used $0.5 \mathrm{M} \mathrm{K}_{2} \mathrm{SO}_{4}$ (buffered with $5 \mathrm{~mm}$ HEPES, $\mathrm{pH}$ 7.25)-filled microelectrodes.

Neurotoxins. Veratridine was obtained from Sigma Chemical Co. (St. Louis, MO) or Aldrich Chemical Co. (Milwaukee, WI.) or was purified from veratrine (Aldrich Chemical Co.) using the method of Kupchan et al. (1953) as modified by McKinney (1982). Veratridine was dissolved in $100 \%$ ethanol to make a stock solution of 10 $\mathrm{mM}$. In control experiments, the equivalent final concentration $(0.5 \%)$ of ethanol had no effect on the resting membrane potential of astrocytes. A stock solution of ScTX(II) purified from the North African scorpion Androctonus australis Hector, was made in glass-distilled water. The stock solutions of veratridine and $\mathrm{ScTx}$ (II) were stored in a refrigerator. A stock soultion of $3.33 \mathrm{~mm}$ TTX in a citrate buffer (Sigma Chemical Co.) was made up in glass-distilled water and kept refrigerated. In control experiments, Na citrate $\left(10^{-6} \mathrm{M}\right)$ had no effect on the veratridine-induced depolarizations. Dilutions of the neurotoxons were made into $1 \mathrm{ml}$ of the HEPES-buffered Ringer's solution and were then added to the perfusion chamber using a syringe.

\section{Results}

Veratridine depolarized the resting membrane potential, and the magnitude of this effect was concentrationdependent (Fig. 1). At $5 \times 10^{-5} \mathrm{M}$, veratridine caused large and long-lasting depolarizations of up to $40 \mathrm{mV}$, while lower concentrations produced transient depolarizations (Fig. 1). When ScTx(II) was added in the presence of veratridine, the duration of the transient depolarizations was prolonged (compare parts $A$ and $B$ of Fig. 2). ScTx(II) by itself had no effect (Fig. $2 C$ ). Altogether, we studied the behavior of 75 individual cells from 18 separate cell cultures whose ages ranged from 15 to 39 days. Only six cells failed to respond to the application of veratridine. While there was some variability in the

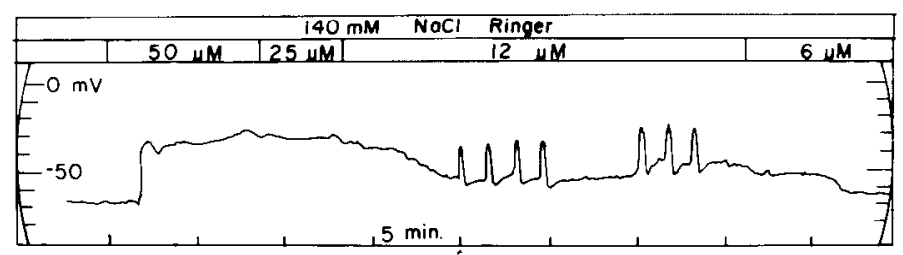

Figure 1. Effect of several different concentrations of veratridine on the resting membrane potential of an impaled cell. Several capacitive artifacts were omitted from the tracings of original records. Addition of the different concentrations of veratridine to the perfusion chamber is indicated at the top. The concentration of veratridine was reduced in steps of onehalf from the original value of $50 \mu \mathrm{M}$ by reducing the volume of fluid in the chamber by one-half and then adding Ringer's solution to the remaining fluid such that the original fluid level was restored.

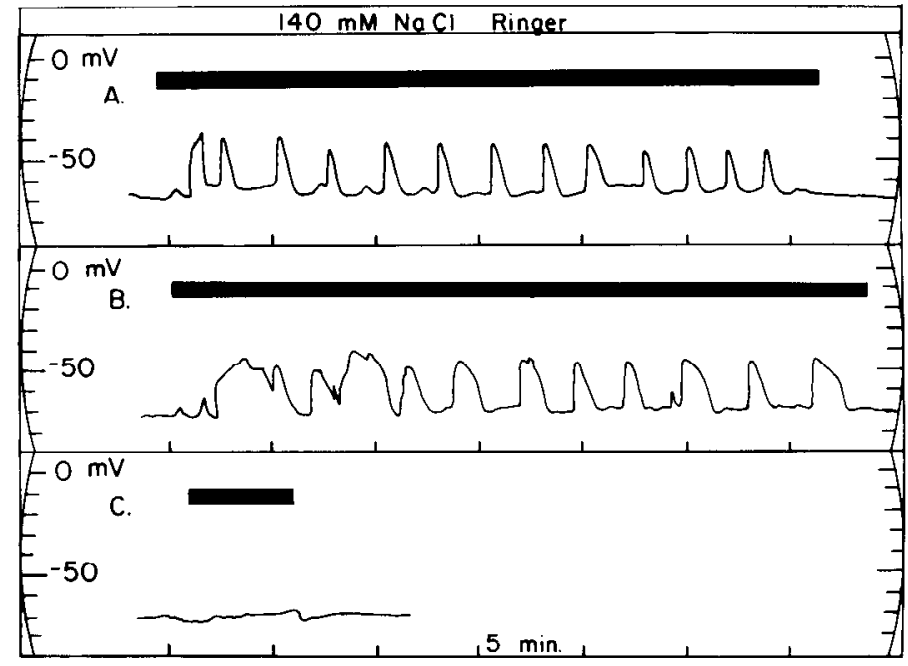

Figure 2. Effect of ScTx(II) on the veratridine-induced depolarizations. Tracings in $A, B$, and $C$ are from the same cell. $A$, Presence of veratridine $\left(1 \times 10^{-4} \mathbf{M}\right)$, represented by the black bar, caused a series of transient depolarizations in this cell that disappeared upon washout. $B$, Effect of inclusion of ScTx(II). The combination of veratridine $\left(1 \times 10^{-4} \mathrm{M}\right)$ and $\operatorname{Sc} T x(I I)\left(2.5 \times 10^{-8} \mathrm{M}\right)$, represented by the black bar, resulted in a prolongation of the depolarizations (compare with $A$ ). The depolarizations disappeared upon washout (not shown). $C$, Effect of ScTx on the resting membrane potential. The presence of ScTx(II) alone $\left(2.5 \times 10^{-8} \mathbf{M}\right)$, represented by the black bar, was without effect on the resting membrane potential.

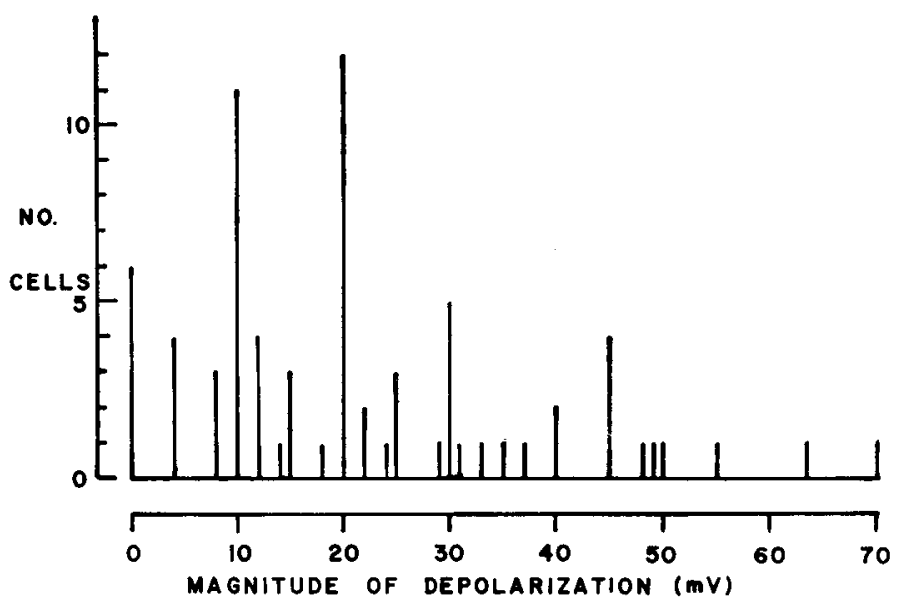

Figure 3. Bar graph of the magnitude (millivolts) of the neurotoxin-induced depolarizations. Data were pooled from all experiments and include veratridine $\left(0.5 \times 10^{-4} \mathrm{M}\right.$ to $2.0 \times 10^{-4}$ M) or veratridine $\left(0.5 \times 10^{-4} \mathrm{M}\right.$ to $\left.2.0 \times 10^{-4} \mathrm{M}\right)$ plus $\alpha-\mathrm{Sc}^{\prime} \mathrm{Tx}$ $\left(1.3 \times 10^{-9} \mathrm{M}\right.$ to $\left.2.5 \times 10^{-7} \mathrm{M}\right)$-induced depolarizations. No significant difference in the magnitude of the depolarizations was seen for veratridine or veratridine plus $\alpha-\mathrm{ScTx}$ (II).

size of the depolarization, the response generally ranged between 10 and $30 \mathrm{mV}$ (Fig. 3).

Since veratridine and ScTx(II) have been thought to alter specifically the gating properties of voltage-sensitive $\mathrm{Na}^{+}$channels in excitable cells, we investigated the possibility that the responsive cells in our primary cultures were not astrocytes. Such cells would have to be a minority since approximately 80 to $90 \%$ of the rounded- 
up cells in our cultures stain for GFAP (Stieg et al., 1980; C. Bowman and H. K. Kimelberg, unpublished observations), and these cells are normally not electrically excitable (Kimelberg et al., 1982b). Nevertheless, we decided to examine directly whether cells that showed a veratridine-induced depolarization also stain for GFAP, a marker considered specific for astrocytes (Schachner et al., 1977; Bignami et al., 1980; Eng, 1980). A cell which exhibited a veratridine-induced depolarization as well as the filamentous pattern of staining for GFAP is shown in Figure 4. Similar results were obtained in six additional cells. We conclude from these results that astrocytes are depolarized by veratridine.

Since the depolarizations were likely to be due to an increase in sodium conductance, the effects of tetrodotoxin were investigated. Addition of TTX $\left(1.6 \times 10^{-8} \mathrm{M}\right)$ blocked transient electrical activity, while smaller concentrations of TTX $\left(1.6 \times 10^{-9} \mathrm{M}\right.$ or $\left.1.6 \times 10^{-10} \mathrm{M}\right)$ were without effect (Fig. 5). This effect of TTX was reversible, as the transient response returned after washout of TTX. The effect of TTX in preventing veratridine plus $\mathrm{ScTx}(\mathrm{II})$-induced depolarization was found in a total of seven cells: at $1.3 \times 10^{-8} \mathrm{M}$ (four cells) and at $1.5 \times 10^{-6}$ M (three cells). Depolarizations induced by veratridine alone were also TTX-sensitive (four cells; $1.5 \times 10^{-6} \mathrm{M}$ TTX).

If $\mathrm{Na}^{+}$plays a role in the veratridine-induced depolarization, then reduction of external $\mathrm{Na}^{+}\left(\left[\mathrm{Na}^{+}\right]_{0}\right)$ should affect the magnitude of the depolarization. Reduction of $\left[\mathrm{Na}^{+}\right]_{0}$ from $140 \mathrm{~mm}$ to $10 \mathrm{~mm}\left(\mathrm{Na}^{+}\right.$replaced by arginine $)$ reversibly reduced the size of the depolarization induced by the combination of veratridine and ScTx(II) (Fig. 6). Similar results were obtained when $\left[\mathrm{Na}^{+}\right]_{0}$ was replaced by either Tris (three cells) or choline (two cells). Clearly, external sodium was responsible for most, if not all, of the changes in membrane potential induced by the combination of neurotoxins.

The preceding results show that astrocytes in primary culture have a chemical inducible $\mathrm{Na}^{+}$channel. Since in the absence of veratridine these $\mathrm{Na}^{+}$channels appear to be closed, we explored the possibility that the channels were strongly inactivated by a voltage-dependent mechanism and could thus be opened by changes in the membrane potential. In excitable cells, hyperpolarization relieves the voltage- and time-dependent inactivation of $\mathrm{Na}^{+}$channels such that the cell membrane can become excitable at the resting membrane potential. Such a longterm $\mathrm{Na}^{+}$inactivation mechanism exists in denervated
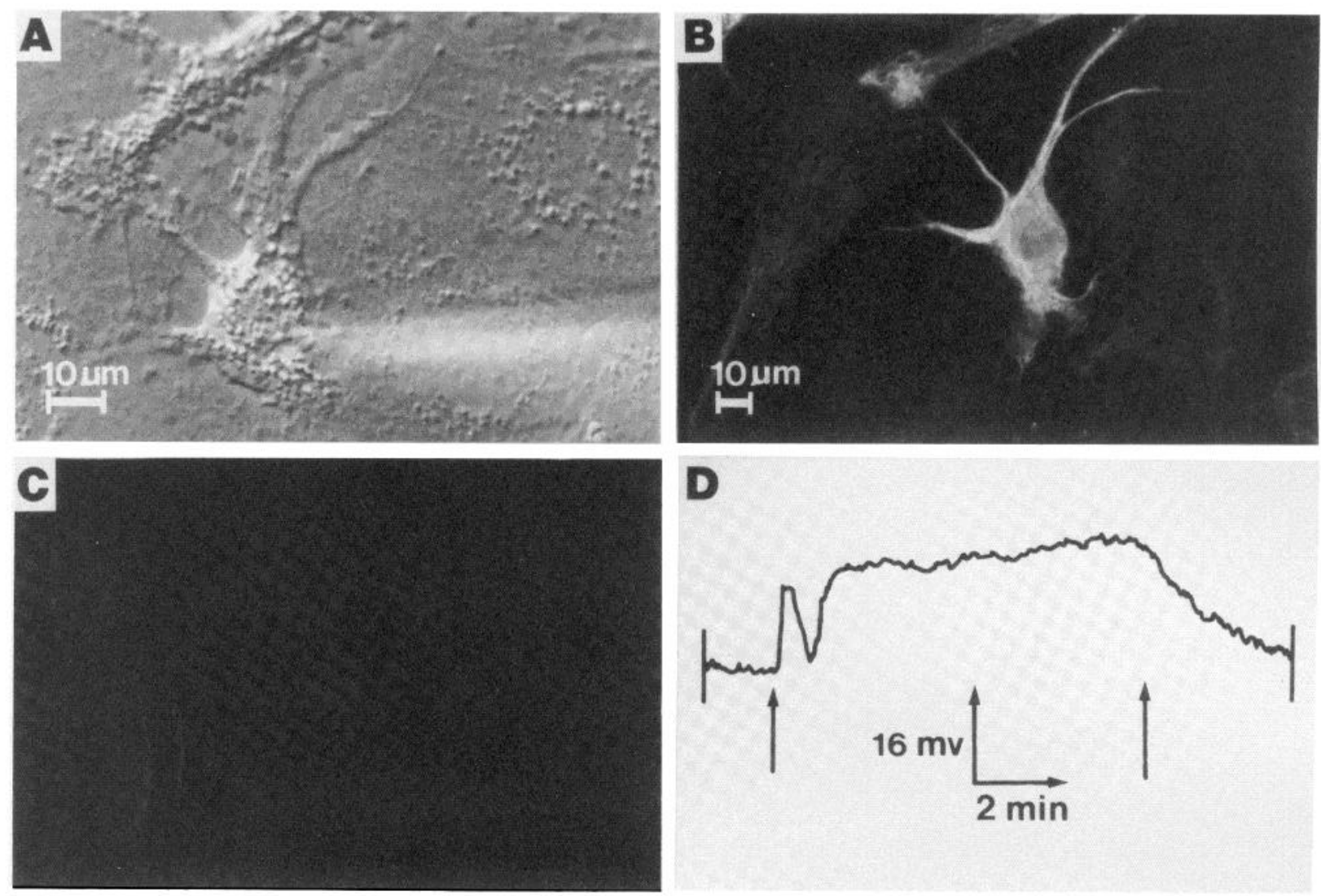

Figure 4. Indirect immunofluorescent detection of GFAP and electrical recording from the same cell. $A$, Cell impaled with a microelectrode filled with $0.5 \mathrm{M} \mathrm{K}_{2} \mathrm{SO}_{4}$. The tip of the microelectrode is just above the plane of focus. Hoffman modulation contrast optics. B, Indirect immunofluorescent detection of GFAP. This is the same cell as in A. See "Materials and Methods" for experimental details. $C$, Control. Nonimpaled cells from the same culture but a different coverslip. Normal rabbit serum (1:50 dilution in PBS). The exposure and magnification were the same as in $B . D$, Electrical recording of a $0.1 \mathrm{mM}$ veratridineinduced depolarization. Resting membrane potential was $-52 \mathrm{mV}$. Veratridine was added at the first arrow. Washout of the drug with Ringer's solution was begun at the second arrow. 


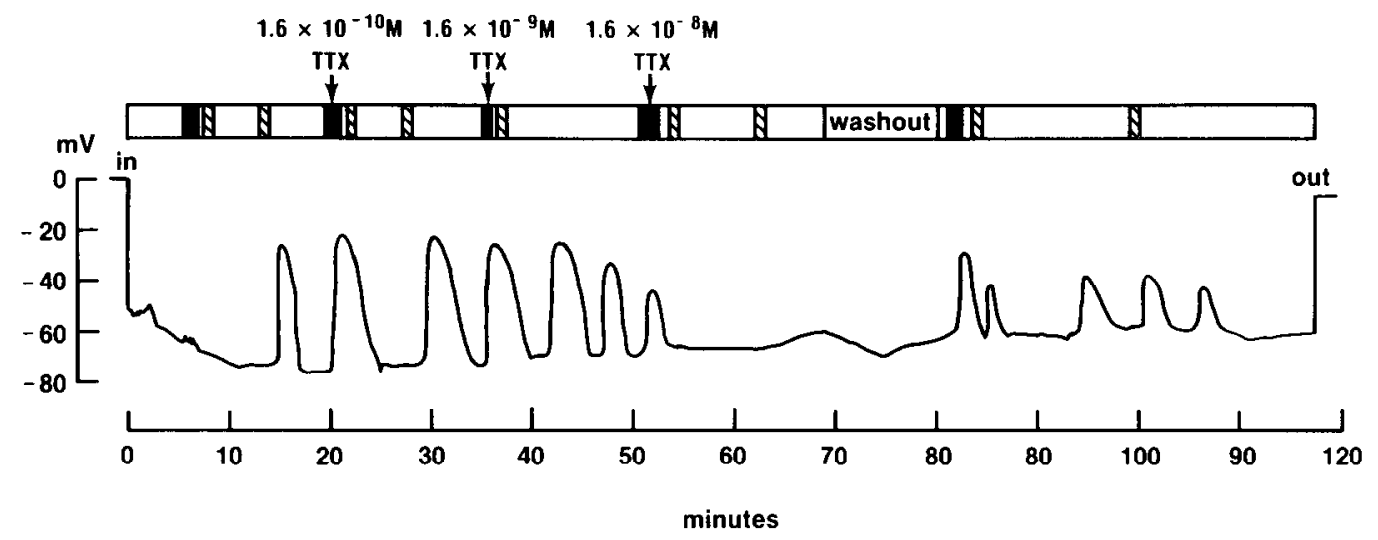

Figure 5. Effect of TTX on the transient depolarizations induced by the combination of veratridine and ScTx(II). The cell was impaled (in) and initially showed a membrane potential of approximately $-52 \mathrm{mV}$, which gradually increased to $-73 \mathrm{mV}$ over a period of $12 \mathrm{~min}$. Veratridine $\left(5 \times 10^{-5} \mathrm{M}\right)$ and $\alpha-\operatorname{ScTx}(\mathrm{II})\left(1.3 \times 10^{-7} \mathrm{M}\right)$ were first added to the bath $5.7 \mathrm{~min}$ after the beginning of the impalement as indicated by the black boxes above the tracing. The width of the black box indicates the period of time over which the neurotoxins were added to the bath. The hatched box indicates the time during which the contents of the perfusion chamber was mixed. Approximately $7 \mathrm{~min}$ after the addition of the neurotoxins, the first transient depolarization appeared. Approximately $20 \mathrm{~min}$ after the impalement, $1.6 \times 10^{-10} \mathrm{M}$ TTX was added to the bath (together with veratridine and $\alpha$-ScTx(II), such that the concentrations of these two neurotoxins were kept constant). The concentration of TTX was progressively increased by factors of 10 at $35 \mathrm{~min}$ and at $51 \mathrm{~min}$. The transient depolarizations disappeared after addition of 1.6 $\times 10^{-8} \mathrm{M}$ TTX. Veratridine, $\alpha$-ScTx(II), and TTX were washed out at $69 \mathrm{~min}$. Veratridine $\left(5 \times 10^{-5} \mathrm{M}\right)$ and $\alpha$-ScTx(II) $(1.3 \times$ $10^{-7} \mathrm{M}$ ) were added to the bath at $80 \mathrm{~min}$, resulting in the reappearance of the transient depolarizations. The microelectrode was withdrawn from the cell at $117 \mathrm{~min}$. There was a $6-\mathrm{mV}$ change in tip potential.
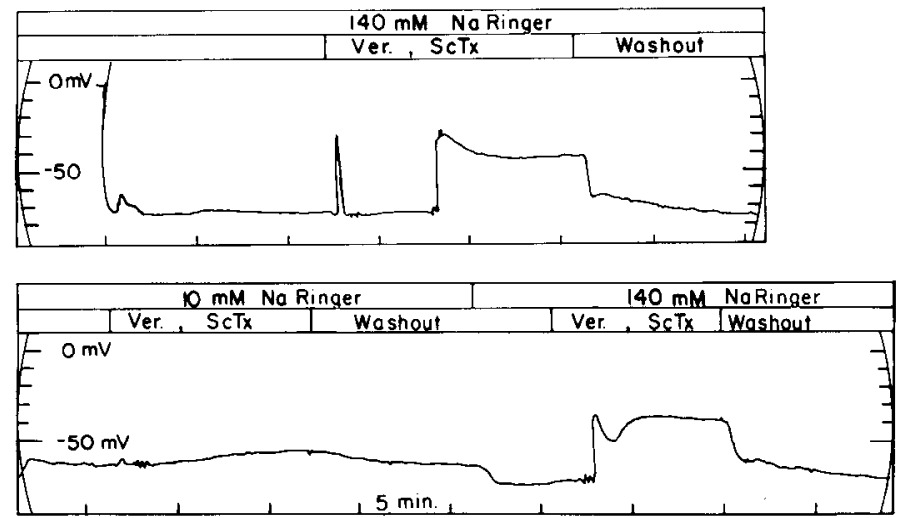

Figure 6. Effect of reducing external $\mathrm{Na}^{+}$on the veratridine plus ScTx-induced depolarizations. Tracings in both panels are from the same cell. Upper panel, Veratridine $\left(5 \times 10^{-5} \mathrm{M}\right)$ and $\mathrm{ScTx}\left(1.3 \times 10^{-8} \mathrm{M}\right)$ produced a sustained depolarization $(30$ $\mathrm{mV}$ ) after a 4-min lag period. The sustained depolarization disappeared upon washout. The initial transient depolarization was observed during the time of addition of the neurotoxins to the bath. Lower panel, Effect of reducing external $\mathrm{Na}^{+}$by molefor-mole replacement by arginine. When external $\mathrm{Na}^{+}$was reduced from $140 \mathrm{~mm}$ to $10 \mathrm{~mm}$, an apparent depolarization (7 $\mathrm{mV}$ ) was initially observed, as seen at the extreme left-hand side of this panel; this response may be due to an inhibition of the $\mathrm{Na}^{+} / \mathrm{K}^{+}$ATPase present in these cells (Kimelberg et al. 1979). In this solution the addition of veratridine $\left(5 \times 10^{-5} \mathrm{M}\right)$ plus ScTx $\left(1.3 \times 10^{-8} \mathrm{M}\right)$ resulted in only a small depolarization $(7 \mathrm{mV})$ that again disappeared upon washout. Increasing the concentration of $\mathrm{Na}^{+}$back to $140 \mathrm{~mm}$ first resulted in an apparent hyperpolarization $(-7 \mathrm{mV})$. Subsequent addition of veratridine $\left(5 \times 10^{-5} \mathrm{M}\right)$ and $\operatorname{ScTx}\left(1.3 \times 10^{-8} \mathrm{M}\right)$ then produced a large sustained depolarization $(30 \mathrm{mV})$ that again disappeared upon washout. and organ-cultured mouse extensor digitorum longus muscles (Henderson and Reynolds, 1978). To see if a similar long-term voltage-dependent sodium inactivation was present in astrocytes, cells were impaled with two microelectrodes. In the absence of veratridinc, there was a linear current-voltage relationship (Fig. 7). Furthermore, no spontaneous depolarization was present after cessation of a long-term (10 to $15 \mathrm{sec})$ hyperpolarizing current pulse (Figs. 7 , inset, and $8 A$ ). By contrast, in the presence of veratridine, cessation of a hyperpolarizing current resulted in a spontaneous transient depolarization of up to $10 \mathrm{mV}$ (Fig. $8 B$ ), as if a voltage-sensitive element was present in the membrane. The depolarization produced by a relatively short-duration ( $1 \mathrm{sec})$ hyperpolarizing pulse was smaller and somewhat delayed (Fig. $8 B$, fourth pulse) as compared to that initiated by a longer 10-sec pulse. The anode break-induced depolarization (Fig. $9 \mathrm{~A})$ was largely sensitive to TTX $\left(1 \times 10^{-8}\right.$ M) (Fig. $9 B$ ). We have observed similar effects of TTX (10 to $60 \mathrm{nM}$ ) in three additional cells and have observed anode break-induced depolarizations (amplitude 2 to 20 $\mathrm{mV}$; duration of 5 to $15 \mathrm{sec}$ ) in the presence of veratridine $(0.1 \mathrm{~mm})$ in seven cells.

\section{Discussion}

The dependence of the magnitude of the veratridineinduced depolarization on $\left[\mathrm{Na}^{+}\right]_{0}$, its inhibition by TTX, and its sensitivity to $\alpha$-Sctro (II) show that astroglia grown in primary culture have chemically inducible $\mathrm{Na}^{+}$ channels. These $\mathrm{Na}^{+}$channels appear to show some aspects of voltage dependence since there was an anode break-induced depolarization, but they differ from the behavior of voltage-dependent $\mathrm{Na}^{+}$channels in excitable cells principally in the long duration of the transient 


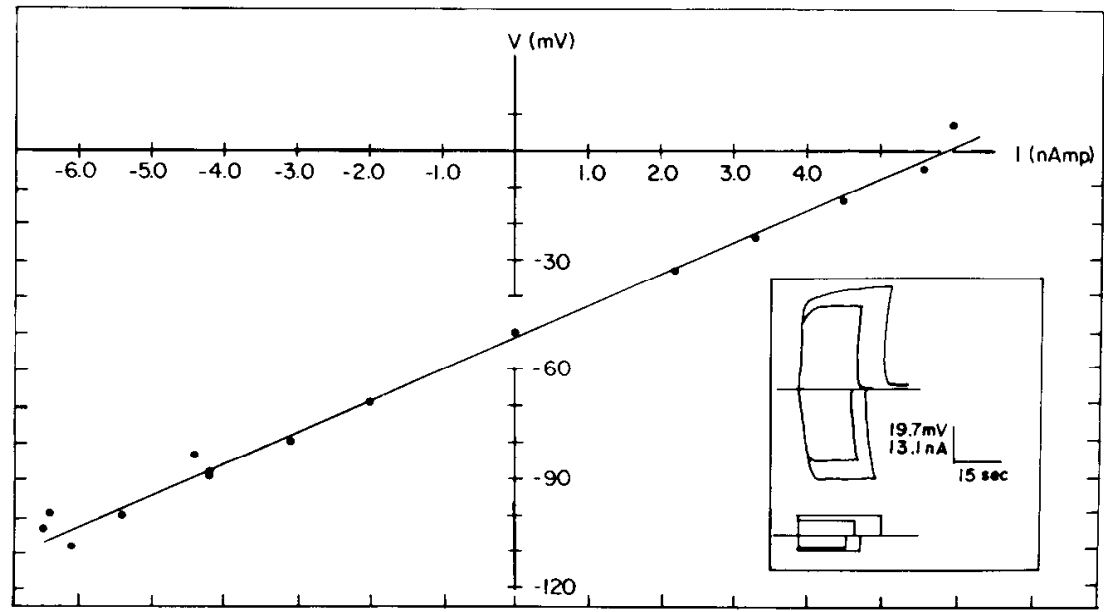

Figure 7. Current-voltage relationship. The cell was impaled with two microelectrodes; one was used to pass current while the other recorded membrane potential. Inset, upper trace, Four examples of the current-induced change in membrane potential. Lower trace, Corresponding current pulses. Deflections in the upward direction indicate depolarization or positive current. The current traces are offset slightly to the left relative to the voltage traces. Curvilinear recordings.

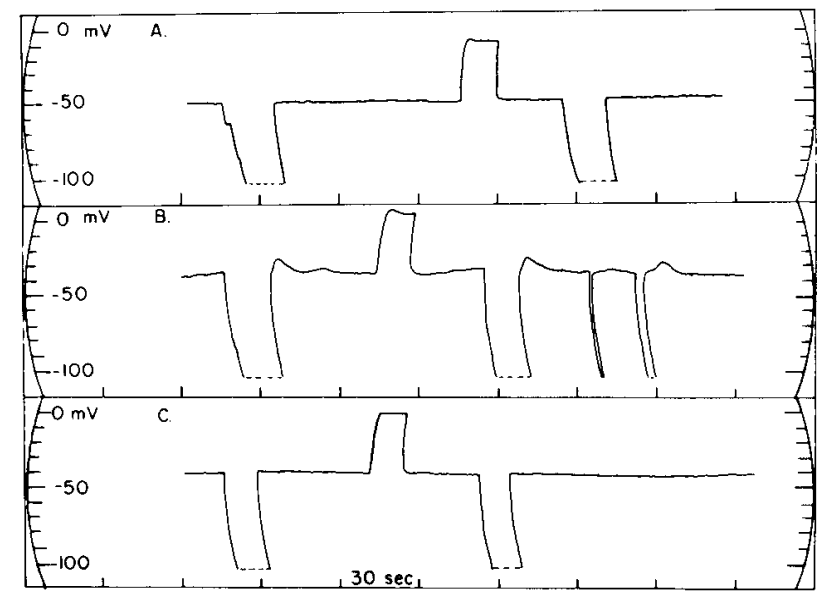

Figure 8. Apparent voltage dependence of the $\mathrm{Na}^{+}$channel. The cell was impaled with two microelectrodes; one was used to pass current pulses while the other monitored the changes in membrane potential. The traces in $A, B$, and $C$ are from the same cell. $A$, Lack of apparent voltage sensitivity in the absence of veratridine. A negative current pulse $\left(9.1 \times 10^{-9} \mathrm{~A}\right)$ resulted in a hyperpolarization of the membrane potential from -60 $\mathrm{mV}$ to $-123 \mathrm{mV}$ (off scale). The duration of the pulse is represented by the dashed line $(10 \mathrm{sec})$. Approximately $60 \mathrm{sec}$ after cessation of the hyperpolarizing pulse, the membrane potential was depolarized from the resting potential to $-10 \mathrm{mV}$ by a positive current pulse $\left(4.9 \times 10^{-9} \mathrm{~A}\right)$. Twenty seconds after cessation of the positive pulse, the membrane potential was again hyperpolarized to $-123 \mathrm{mV} . B$; Anode break-induced depolarization in the presence of veratridine $\left(5 \times 10^{-5} \mathrm{M}\right)$ suggesting voltage dependence. Addition of veratridine caused the membrane potential to depolarize from the resting potential to about $-38 \mathrm{mV}$, and several oscillations in the membrane potential were sometimes present, but not during the period of the recording shown here. The hyperpolarizing and depolarizing current pulse regime was repeated. $C$, Reversibility of the response. Veratridine was washed out with approximately 30 $\mathrm{ml}$ of Ringer's solution over a period of $4 \mathrm{~min}$. The current pulse regime then failed to elicit anode break depolarization.

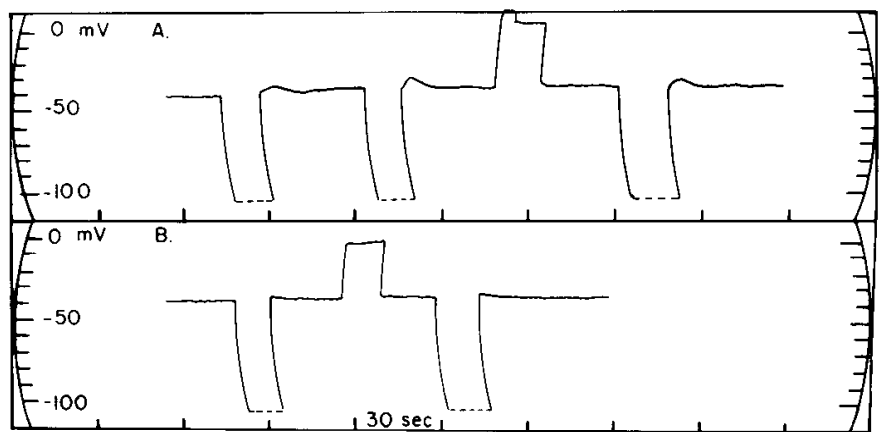

Figure 9. TTX sensitivity of the anode break depolarization. Electron recordings shown in this figure and in Figure 7 are from the same cell. $A$, Anode break-induced depolarization in the presence of veratridine $\left(5 \times 10^{-5} \mathrm{M}\right)$. The cessation of longterm hyperpolarizing pulses resulted in anode break-induced depolarization. Membrane potential was hyperpolarized to $-120 \mathrm{mV}$ with $-8.2 \times 10^{-9} \mathrm{~A}$ (first, third, and fourth pulses). $B$, Sensitivity of anode break-induced depolarization to TTX $\left(1 \times 10^{-8} \mathrm{M}\right)$. The current pulse regime was repeated in the presence of TTX and resulted in only a very small anode breakinduced depolarization.

depolarization which follows hyperpolarization. The anode break-induced depolarization is also small in magnitude, but this may be due to a still dominant $\mathrm{K}^{+}$ conductance.

Some other nonexcitable cells also seem to have sodium channels based on neurotoxin-induced and tetrodotoxin-sensitive uptake of ${ }^{22} \mathrm{Na}$. Cultured fibroblasts derived from human lung and dermal tissue, normal human "glial-like" cells, and human malignant glioma cells show a neurotoxin-induced uptake of ${ }^{22} \mathrm{Na}$. However, such effects were not seen in $\mathrm{C}_{6}$ cells (a rat glioblastoma) and normal or transformed 3T3 cells (Munson et al., 1979). $\mathrm{C}_{9}$ cells, derived from a rat bladder metastasis of a $N$-ethyl- $N$-nitrosurea-induced rat brain tumor, show a neurotoxin-induced and tetrodotoxin-sensitive 
uptake of ${ }^{22} \mathrm{Na}$ as well as a slow wave activity (i.e., transient depolarizations) induced by sea anemone toxin II, and the effect of the toxin was sensitive to TTX (Romey et al., 1979). The authors suggested that the channels were immature since they were insensitive to electrical stimulation. Since some but not all cells in culture show $\mathrm{Na}^{+}$channels, it is unlikely that the presence of toxin-induced channels represents a general aberration due to the conditions of cell culture.

The incomplete inhibition by 'T'I'X and the delayed depolarization induced by relatively short-term hyperpolarizing current pulses found in the primary astrocyte cultures are characteristic of the long-term $\mathrm{Na}^{+}$inactivation found in organ cultured muscles (Henderson and Reynolds, 1978). We have not investigated systematically the effects of further increases in TTX concentration. Under the usual conditions of culture, astrocytes do not have voltage-dependent $\mathrm{Na}^{+}$channels, but veratridine seems to "uncover" or confer on the cell such $\mathrm{Na}^{+}$ channels which do show some degree of voltage sensitivity after hyperpolarization. One possible explanation of the results is that veratridine itself could somehow form a voltage-dependent channel. This seems unlikely because in experiments with bilayer lipid membranes the addition of veratridine was without effect on the membrane current-voltage relationship (B. Rudy and C. Edwards, unpublished observations).

There have been a few reports on the effects of neurotoxin on the electrophysiological properties of other glial preparations. Electrically silent Schwann cells surrounding the giant nerve fiber of the squid were found to be depolarized by neurotoxins, and this depolarization was blocked by tetrodotoxin (Villegas et al., 1976). In contrast, glial cells in the denervated optic nerve of the mudpuppy (Neclurus maculosa) do nol show TTX-sensitive, neurotoxin-induced depolarizations (Tang et al., 1979). These studies on glial cells in squid and Necturus and the present work suggest that some but not all glial cells have sodium channels which can be opened by the action of the same neurotoxins. While the physiological role of this $\mathrm{Na}^{+}$channel is unclear, these channels may be responsible for the small $\mathrm{Na}^{+}$influx present in most cells (Dean, 1941). These channels may be present in many cells; they are possibly closed more often than they are open, but they can be opened artificially by veratridine or other chemical agents of the type used in these experiments. Alternatively, such channels in some glial cells, including mammalian astroglia, may be responsive to endogenous effectors (i.e., a veratridine-like agent). However, this suggestion is speculative at this time since we are not aware of any evidence for the presence of such in vivo effectors or, indeed, whether veratridine can depolarize mammalian astroglial cells in vivo.

\section{References}

Berwald-Netter, Y., D. Beaudoin, and F. Couraud (1983) Contribution to the characterization of astrocyte membrane properties. J. Neurochem. 41: S3.

Bignami, A., D. Dahl, and C. D. Reuger (1980) Glial fibrillary acidic protein (GFA) in normal neural cells and in pathological conditions. In Advances in Cellular Neurobiology, S. Fedoroff and L. Hertz, eds., pp. 285-310, Academic Press,
New York.

Bowman, C., C. Edwards, and H. K. Kimelberg (1983a) Tetrotodotoxin sensitive depolarizations induced by veratridine and $\alpha$-scorpion toxin in primary astrocytes in culture. Biophys. J. 41: 386a.

Bowman, C., C. Edwards, and H. K. Kimelberg (1983b) Veratridine causes astrocytes in primary culture to become excitable. Soc. Neurosci. Abstr. 9: 448.

Dean, R. B. (1941) Theories of electrolyte equilibrium in muscle. Biol. Symp. 3: 331-348.

Eng, L. F. (1980) The glial fibrillary acidic (GFA) protein. In Proteins of the Nervous System, R. Bradshaw and D. Schneider, eds., pp. 85-117, Raven Press, New York.

Eng, L. F., and L. J. Rubinstein (1978) Contribution of immunocytochemistry to problems of human cerebral tumors. J. Histochem. Cytochem. 26: 513-522.

Frangakis, M. V., W. J. Koopman, H. Kiyono, S. M. Michalek, and J. R. McGhee (1981) An enzymatic method for preparation of dissociated murine Peyer's path cells enriched for macrophages. J. Immunol. Methods 48: 33-45.

Henderson, E. G., and L. S. Reynolds (1978) Removal of slow inactivation in denervated and organ-cultured mouse skeletal muscle: Modification by tetrodotoxin. J. Pharmacol. Exp. Ther. 207: 1032-1040.

Hertz, L. (1982) Astrocytes. In Handbook of Neurochemistry, Ed. 2, A. Lajtha, ed., Vol. 1, pp. 319-355, Plenum Press, New York.

Kimelberg, H. K. (1983) Primary astrocyte cultures-a key to astrocyte function. Cell. Mol. Neurobiol. 3: 1-16.

Kimelberg, H. K., C. L. Bowman, S. Biddlecome, and R. S. Bourke (1979) Cation transport and membrane potential properties of primary astrocytes in cell culture from neonatal rat brains. Brain Res. 177: 533-500.

Kimelberg, H. K., P. E. Stieg, and J. E. Mazurkiewicz (1982a) Immunocytochemical and biochemical analysis of carbonic anhydrase in primary astrocyte cultures from rat brain. $\mathrm{J}$. Neurochem. 39: 734-742.

Kimelberg, H. K., H. Hirata, C. L. Bowman, and J. Mazurkiewicz (1982b) Effects of $\mathrm{K}^{+}, \mathrm{Na}^{+}$, and $\mathrm{Cl}^{-}$on membrane potentials and IV curves of primary astrocyte cultures. Soc. Neurosci. Abstr. 8: 238.

Koppenhoffer, E., and H. Schmidt (1968) Die Wirkung von Skurpiongift auf die lonenstrome des Ranvierschen Schnurrings. Pflugers Arch. 303: 133-149.

Kupchan, S. M., D. Lavie, C. V. DeLiwala, and B. Y. A. Andoh (1953) Schoenocaulon alkaloids. I. Active principles of Schoencaulon officinala. Cevacine and Protocevine. J. Am. Chem. Soc. 75: 5519-5524.

McKinney, L. (1982). Sodium permeability of frog skeletal muscle in the absence and presence of veratridine. Ph.D. Thesis, Washington University, St. Louis, MO.

Moonen, G., G. Franck, and E. Schoffeniels (1980) Glial control of neuronal excitability in mammals. I. Electrophysiological and isotopic evidence in culture. Neurochem. Int. 2: 299-310.

Munson, R., B. Westermark, and L. Glaser (1979) Tetrodotoxin sensitive sodium channels in normal human fibroblasts and normal human glial-like cells. Proc. Natl. Acad. Sci. U. S. A. 76: 6425-6429.

Narahashi, T. (1974) Chemicals as tools in the study of excitable membranes. Physiol. Rev. 54: 813-899.

Orkand, R. K. (1977) Glial cells. In Handbook of Physiology. Sec. 1: The Nervous System, E. R. Kandel, ed., Vol. I, pp. 855-875, American Physiological Society, Bethesda, MD.

Reiser, G., and B. Hamprecht (1983) Sodium-channels in nonexcitable glioma cells, shown by the influence of veratridine, scorpion toxin, and tetrodotoxin on membrane potential and on ion transport. Pflugers Arch. 397: 260-264.

Reiser, G., F. Loffler, and B. Hamprecht (1983) Tetrodotoxin- 
sensitive ion channels characterized in glial and neuronal cells from rat brain. Brain Res. 261: 335-340.

Romey, G., Y. Jacques, H. Schweitz, M. Fosset, and M. Lazdunski (1979) The sodium channel in non-impulse cells; interaction with specific neurotoxins. Biochim. Biophys. Acta 556: 344-353.

Schachner, M., E. T. Hedley-Whyte, D. W. Hsu, G. Schoonmaker, and A. Bignami (1977) Ultrastructural localization of glial fibrillary acidic protein in mouse cerebellum by immunoperoxidase labelling. J. Cell Biol. 75: 67-73.

Schousboe, A. (1980) Primary cultures of astrocytes from mammalian brain as a tool in neurobiological research. Cell. Mol. Biol. 26: 505-513.

Somjen, G. G. (1975) Electrophysiology of neuroglia. Annu. Rev. Physiol. 37: 163-190.
Stieg, P. E., II. K. Kimelberg, J. E. Mazurkiewicz, and G. A. Banker (1980) Distribution of glial fibrillary acidic protein and fibronectin in primary astroglial cultures from rat brain. Brain Res 199: 493-500.

Tang, C. M., G. R. Strichartz, and R. K. Orkand (1979) Sodium channels in axons and glial cells of the optic nerve of $\mathrm{Nec}$ turus maculosa. J. Gen. Physiol. 74: 629-642.

Ulbricht, W. (1969) The effect of veratridine on excitable membranes of nerve and muscle. Ergeb. Physiol. Biol. Chem. Exp. Pharmakol. 61: 18-71.

Villegas, J., C. Sevcik, F. Barnola, and R. Villegas (1976) Grayanotoxin, veratrine and tetrodotoxin sensitive sodium pathways in the Schwann cell membrane of squid nerve fibers. J. Gen. Physiol. 67: 369-380. 